\title{
Why Do They Enroll in This Course? Undergraduates' Course Choice From a Motivational Perspective
}

\author{
Hye Rin Lee ${ }^{1 *}$, Luise von Keyserlingk ${ }^{1}$, Richard Arum ${ }^{1}$ and Jacquelynne Sue Eccles ${ }^{1,2}$ \\ ${ }^{1}$ University of California, Irvine, School of Education, Irvine, CA, United States, ${ }^{2}$ Australian Catholic University, Institute for Positive \\ Psychology and Education, Sydney, NSW, Australia
}

Why do students pick various courses? Interdisciplinary research has highlighted the role of structural constraints, normative expectations, and individual motivation as the joint influences of agency and structure in the service of life goals. Here, we examined undergraduates' reasons for course choices for their most difficult and most important courses. We compared the reasons for non-major vs. major courses, for freshman vs. juniors, and across different disciplines. College students selected courses that fulfilled their major or breadth requirements, particularly in their freshman year. STEM courses

OPEN ACCESS

Edited by:

Bernhard Ertl,

Munich University of the Federal Armed Forces, Germany

Reviewed by: Brett D. Jones,

Virginia Tech, Blacksburg, VA,

United States

Martina Blašková,

Police Academy of the Czech

Republic, Czechia

*Correspondence:

Hye Rin Lee

hyer@uci.edu

Specialty section:

This article was submitted to Educational Psychology, a section of the journal Frontiers in Education

Received: 13 December 2020 Accepted: 08 February 2021

Published: 22 March 2021

Citation:

Lee $H$, von Keyserlingk $L$, Arum $R$ and Eccles JS (2021) Why Do They Enroll in This Course? Undergraduates' Course

Choice From a

Motivational Perspective.

Front. Educ. 6:641254.

doi: $10.3389 /$ feduc.2021.641254 were taken more for career development reasons than other disciplines, particularly humanities courses; social sciences courses were taken more for interest than STEM courses; and humanities courses were taken more for intellectual broadening than STEM courses.

Keywords: course choice, college students, motivation, reasons for enrollment, group differences, descriptives

\section{INTRODUCTION}

Why do college students pick their college courses? College students in the United States choose classes for a variety of reasons including interest (Renninger and Hidi, 2015), career skills (Reese and Miller, 2006), major requirement (Eccles and Wigfield, 2020), or merely desire to fulfill a general educational requirement (Johnston et al., 1991). Structural constraints, normative expectations and individual motivation are factors posited by sociologists and psychologists that point to the joint influences of agency and structure in the service of life goals. Structural constraints undoubtedly influence individual choices (Settersten and Gannon, 2005; Archer, 2014). College students likely have different levels of freedom to choose their courses depending on the policies of their schools, majors, and year of studying. Majors in computer sciences and engineering, for example, typically have more required courses than majors in the social sciences and humanities. Similarly, students may need to fulfill more general education requirements or major requirements in their freshmen and sophomore years so that they can focus on their major or their own interests more in their junior and senior year. Therefore, students of certain majors or in their early years might invoke more structure-oriented reasons (such as major and educational requirements) more frequently than older students.

Virtually all theories of motivated behavior stress the relation between activity engagement and the reasons a person has for engagement (e.g., Situated Expectancy-Value Theory, SelfDetermination Theory, Interest Theory, Achievement Goal Theory, etc.). Various theorists have argued that exchanging for an extrinsic rather than an intrinsic reason in academic tasks will lead to less engaged learning strategies and greater likelihood of giving up if the tasks get difficult (Ryan and Deci, 2000; Deci et al., 2001; Meece et al., 2006; Schunk et al., 2008). Furthermore, Situated 
Expectancy-Value Theory (SEVT) theorists argue that the more reasons one has for engaging in an achievement task, the higher will be the subjective task value of that particular task to the individual, and thus the higher motivation will be to engage fully in the task (Eccles and Wigfield, 2020).

These various theoretical perspectives all suggest that knowing the reasons why students enroll in courses will help us understand their engagement in these courses. Knowing the reasons why today's United States college students are taking their courses is also central to current discussions about the meaning and function of higher education in the United States. But what do we know about the reasons college students take various courses? Not very much. There has been substantial work on predictors of taking STEM courses. For instance, SEVT scholars predict that course choice is driven most directly by students' success expectation in the course and the subjective task value the students attach to it (Eccles and Wigfield, 2020). Similarly, Social Cognitive Career theorists argue that a sense of high personal efficacy for success is a major driver of course choice (Lent et al., 2002). By and large, both of these hypotheses are well supported by empirical studies: students' pick college courses in which they expect to succeed. (Lent et al., 2008; Guo et al., 2015; von Keyserlingk et al., 2020), which are important for their future goals (Durik et al., 2006; Lauermann et al., 2015), vital to their identity (Durik et al., 2006; Lauermann et al., 2015), and which they expect to be enjoyable and interesting (Gottfried et al., 2013; Lauermann et al., 2017).

Besides interests, expectations and goals, college students also report quite practical reasons for course choices. Both qualitative and quantitative studies have revealed that students choose courses based on the day and time a course is offered, the requirements students have to fulfill, and characteristics of the course instructor (Chambliss, 2014; Dagogo et al., 2019; Galotti and Umscheid, 2019). For example, as students in their freshman and sophomore year have less flexibility in choosing their courses compared to their junior and senior year, they may choose to take a course more to fulfill their general education requirements.

Taken together, the existing literature suggests that several motivationally relevant beliefs (e.g., success expectations, goals, subjective task values) and situational constraints and norms (e.g., college and major requirements) influence students' choice of courses. But very few studies have actually investigated both sets of options simultaneously. Even fewer studies have considered both group and individual differences simultaneously. Empirical research on course and major choices has often focused on individual and group differences in these motivational beliefs and goals to explain differences in course choices in different domains (e.g., courses in math vs. language focused domains). Much less research has investigated the link between students' reasons to enroll in specific courses and both student and course characteristics.

It is also likely that there are within-person differences in the reasons students give across courses, and consequently in the ways in which a given student allocates their engagement differently across their various courses. In SEVT, for example, it is predicted that putting time and energy into one course takes away from the time available for other courses, thus creating a cost value for every course taken. This possibility led us to ask each student about two different courses: one they perceived as very important and one they perceived as very difficult. Do they choose their difficult courses because they are required, because they want to acquire important but difficult skills, and/or because they expect to succeed in the course? Are they more likely to give external reasons like general education requirements? Inherent in Self-Determination Theory (SDT) and SEVT is the idea that as individuals become more identified with a domain (e.g., "I am a math person, or becoming a biology person is core to my personal identity," which is known as attainment value), they should have more non-extrinsic reasons for taking major courses than nonmajor courses. To our knowledge, no one has studied these questions.

Although some studies have examined the relationship between choice and academic outcomes (e.g., Eccles et al., 2004; von Mizener and Williams, 2009), there is a gap explicitly looking at the various reasons for choice of courses with different course characteristics, despite the fact that all major theories of motivation stress a link between students' reasons for taking specific courses and their engagement in the course. In the present paper, we investigated students' reasons for course enrollment in two courses. In addition, we examined students' reasons for course enrollment in non-major and major requirement courses. Finally, we explored if students of different grade levels and disciplines choose their courses because of different reasons. Our research questions are:

RQ1. What reasons do students report overall for their course choices?

RQ2. Do students report different reasons for their most important vs. most difficult course?

RQ3. Do students report different reasons for non-major requirement vs. major requirement courses?

RQ4. Do freshmen report different reasons for their course choices than juniors?

RQ5. Does the discipline of the course influence the reasons given for students' most difficult and most important course?

\section{METHOD}

\section{Participants}

We used data from an ongoing longitudinal study in one large, highly diverse public university in California. The study was designed to investigate undergraduate's experiences and success. All freshman and junior students in the 2019-20 academic year were eligible to participate. Freshman and juniors were recruited through email for participation and $10 \%(N=1,275)$ of the eligible students consented (see Supplementary Table S1 for more details). From there, 359 participants consented to participate in an in-depth version of the study with weekly surveys about ability beliefs, academic experiences, and goals. 312 students completed the survey questions about the reasons for their course choices. For our purposes, we only included students who declared two different courses as their most difficult and most important course. We, however, examined the reasons for courses chosen 
using the whole sample, and found similar results for the ratings of importance for each reason (refer to Supplementary Figures S1, S2). The final sample consisted of $N=214$ students, $71 \%$ female; $71 \%$ freshman, $29 \%$ juniors; $40 \%$ in social sciences, education, and business; $27 \%$ in biology and health sciences; $18 \%$ in physical sciences, computer sciences, and engineering; 6\% in humanities and arts; and $8 \%$ undeclared in their major.

\section{Materials and Procedures}

After students consented to participate, they received online surveys on a weekly basis across the 2019-20 academic year. We used data that were collected during the first week of the academic term in fall 2019. Participants were asked to choose the course that they expected to be the most difficult and most important from a list of their enrolled courses. In our analysis, we define the most difficult course and the most important course as types of courses. For each type of course, participants were asked to rank the importance of 11 reasons for course enrollment (see Supplementary Appendix A). The list reasons were finalized through having discussions amongst our research team. We also received feedback on the larger survey from the Student Affairs office who regularly interact with students.

The reasons were:

$\{\mathbf{X X}\}$ is required in your major

$\{\mathbf{X X}\}$ fulfills a general education requirement

It will be easy to get a good grade in $\{\mathbf{X X}\}$

You are well prepared to do well in $\{\mathbf{X X}\}$

You have the intellectual talent to do well in $\{\mathbf{X X}\}$

$\{\mathbf{X X}\}$ will be interesting

$\{\mathbf{X X}\}$ will broaden your horizon

$\{\mathbf{X X}\}$ will challenge you to develop yourself

$\{\mathbf{X X}\}$ will help you develop important skills for the career you want

Your friend(s) is (are) taking $\{\mathbf{X X}\}$

Your parents want you to take $\{\mathbf{X X}\}$

\section{Data Analysis}

Quantitative data was analyzed using SPSS Version 27.0 (IBM Corp. Released, 2020). R-Studio 3.5.2 (R Core Team, 2018) was used to create figures/graphs.

All course reasons were numerically re-coded such that the reason was coded 5 , if a student selected it as the top important reason. The reason was coded 4 , if selected as the second and third most important reason. It was coded 1 , when selected as the least important reason, and 2 if it was selected as the second and third least important reason. Reasons that were not selected as important or unimportant reasons were coded 3.

Major designated required course was coded into two categories: major designated required course or non-major designated required course. We used the university website to determine which courses were considered a major requirement or not based on each student's declared major. The discipline of each course was coded into five categories: social sciences, education, and business; biology and health sciences; physical sciences, computer sciences, and engineering; humanities and arts; and other. We used the university website to determine which reported courses came from which school.

\section{RESULTS}

As displayed in Figure 1, students varied in the extent to which they endorsed each different course reason. The boxplot, which includes lines for the $10^{\text {th }}$ and 90th percentile and boxes for the 25th though 75th percentile of values, showed that the most commonly chosen reasons for course choice were "major requirement" and "wanted career skills." The least commonly chosen reasons for course choice were "easy to get a good grade," "friend(s) are taking it," and "parents want you to take it."

\section{Most Difficult and Important Course by Course Reasons}

We compared reasons for most difficult vs. most important course using an 11 by 2 repeated measures ANOVA (reason by course type). Course reason ratings differed significantly from each other, $F(7.762,1629.977)=207.461, p \leq 0.001, \eta_{p}^{2}=0.497$ with fulfilling a major requirement being rated as the most important (see Figure 1; Supplementary Table S2 for frequencies). There was also a statistically significant interaction between course reasons and course type, $F(8.325$, $1748.168)=15.273, p \leq 0.001, \eta_{p}^{2}=0.068$. Pairwise comparisons using Bonferroni correction ${ }^{1}$ indicated that the mean score on the ratings of course reasons for the most difficult course were significantly different than the most important course with: fulfilling a general education requirement (most difficult course, $3.69 \pm 0.968^{2}$; most important course, $3.16 \pm 0.852$; $p \leq 0.001$ ) and challenge to develop yourself (most difficult course, $3.49 \pm 0.842$; most important course, $3.15 \pm 0.772$; $p \leq$ 0.001 ) having higher student ratings for difficult courses than important courses; and well prepared (most difficult course, $2.85 \pm 0.500$; most important course, $3.08 \pm 0.668 ; p \leq 0.001$ ), interesting (most difficult course, $3.08 \pm 0.850$; most important course, $3.53 \pm 0.835 ; p \leq 0.001$ ), and career skills (most difficult course, $3.46 \pm 0.927$; most important course, $3.81 \pm 0.927$; $p \leq$ 0.001 ) having higher student ratings for important courses than difficult courses. Taken together, these findings suggest that students choose their most important course reasons related to depth of interest, preparation, and development of career skills, while their most difficult course was chosen more often around breadth (i.e., general education requirement or challenge).

\footnotetext{
${ }^{1}$ Bonferroni adjustment was calculated by dividing the alpha-level of 0.05 by the number of comparisons. That is, the LSD $p$-value for a pairwise comparison was calculated by 0.05 divide by the number of comparison (i.e., unadjusted $p$-value). We report the corrected $p$-value, which multiplies the unadjusted $p$-value by the number of comparisons; if this value is less than 0.05 , then we concluded that the difference was significant. This method was used for subsequent analyses. ${ }^{2}$ We report Mean \pm SD for all values in the results section.
} 


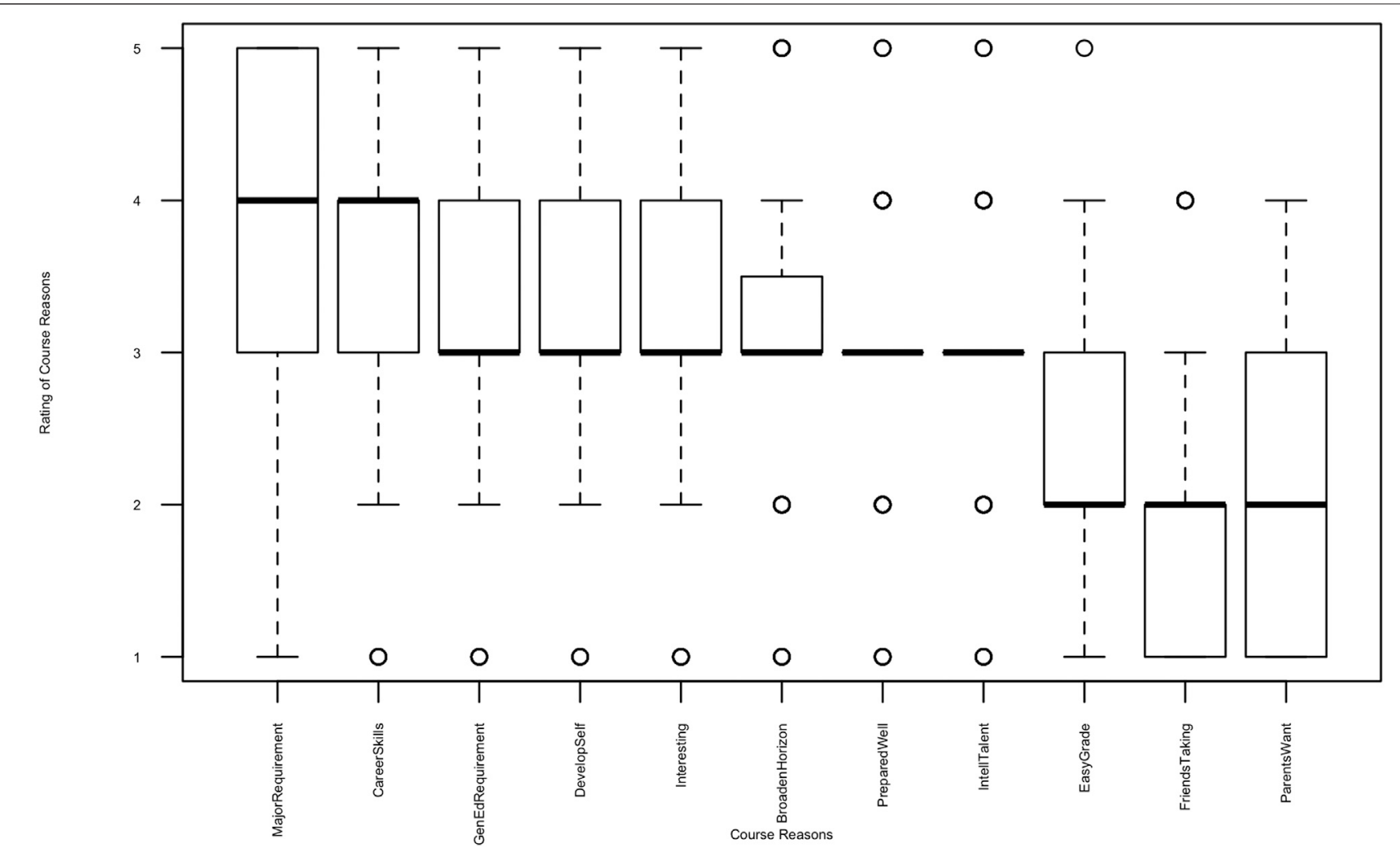

FIGURE 1 | Boxplot of course choice reasons. 1 = the least important reason choice, 2 = the second and third least important reason choices, $3=$ not the least nor most important reason choice, 4 = the second and third most important reason choice, $5=$ the most important reason choice.

\section{Major Designated Required Course and Course Reasons}

Because major requirement was one of the most important reasons for course choice, we examined frequencies and ran a repeated measures ANOVA examining course reasons as a within-subject factor and major (i.e., major designated required course or non-major designated required courses course) and as a between-subject factor predicting the rating of course reasons. The repeated measures ANOVA revealed a statistically significant interaction between course reasons and major designated required course, $F(8.393$, $3206.11)=24.065, p \leq 0.001, \eta_{p}^{2}=0.059$. The mean levels in Figure 2 show that respondents differed in their endorsement of course reasons when comparing the major designated required courses and other courses. Because we defined major designated required course based on the declared major of the student and the formal course requirements of the major, students may or may not have identified "major requirement" as a prominent reason for taking the course. According to pairwise comparisons using Bonferroni correction, mean scores on the rating of course reasons for major designated required courses were significantly different than non-major designated required courses. Major designated required courses were associated with endorsement of career skills as a reason for the course choice (non-major designated required courses, $3.29 \pm$ 0.935; major designated required courses, $3.79 \pm 0.899 ; p \leq$ 0.001 ) as well as, unsurprisingly, student reports of course major requirement as a reason for taking the course (non-major designated required courses, 3.31 \pm 1.012; major designated required courses, $4.31 \pm 0.908$; $p \leq 0.001$ ). Major designated required courses were associated with lower levels of reports of general education requirement as a reason for taking the course (non-major designated required courses, $4.11 \pm 0.984$; major designated required courses, $3.17 \pm 0.778$; $p \leq 0.001)$ or challenge to develop yourself as a reason for taking the course (non-major designated required courses, $3.48 \pm 0.926$; major designated required courses, $3.23 \pm$ $0.763 ; p=0.01)$.

Frequencies by course type showed that $70.25 \%$ of students chose fulfilling a major requirement as their highest ranked reason to choose their most difficult major requirement course (refer to Supplementary Table S3). Fulfilling a major requirement was followed by developing career skills (14.05\%) and challenge to develop self $(7.44 \%)$ as important reasons to choose their most difficult major requirement course. On the other hand, frequencies showed that $56.34 \%$ of students chose general education requirement as their most important 

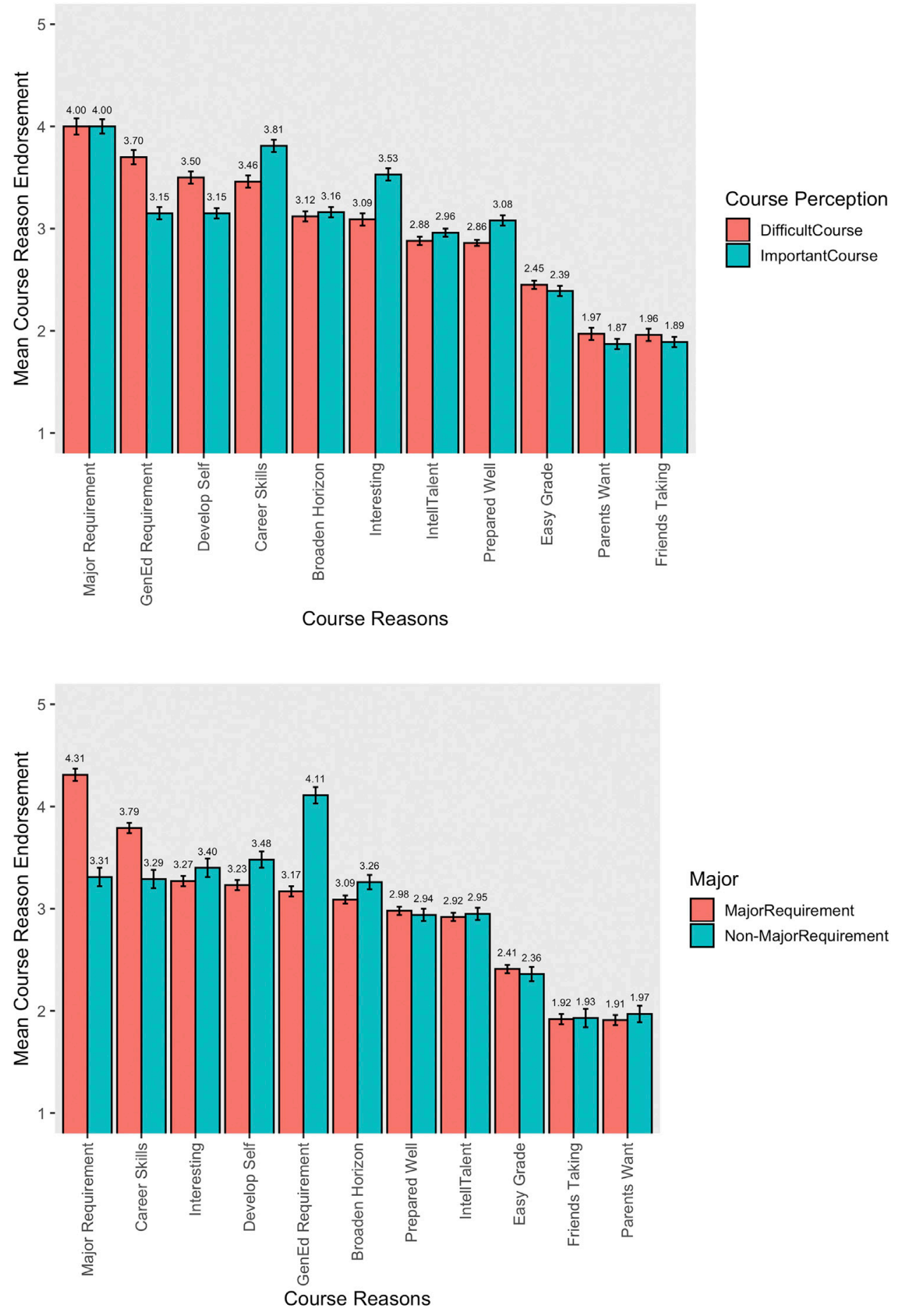

FIGURE 2 | Endorsement of course choice reasons for course perception and major requirement. Group comparison on endorsement of course choice reasons for the most difficult course and most important course (top) and major designated required course and non-major designated required course (bottom). Mean and standard errors are presented; 1 = the least important reason choice, 2 = the second and third least important reason choices, $3=$ not the least nor most important reason choice, 4 = the second and third most important reason choice, 5 = the most important reason choice.

reason to choose their most difficult non-major requirement course (refer to Supplementary Table S3). Fulfilling a general education requirement was followed by fulfilling a major requirement (14.08\%), developing career skills (12.68\%), and challenge to develop self $(12.68 \%)$ as important reasons to choose their most difficult non-major requirement course. 


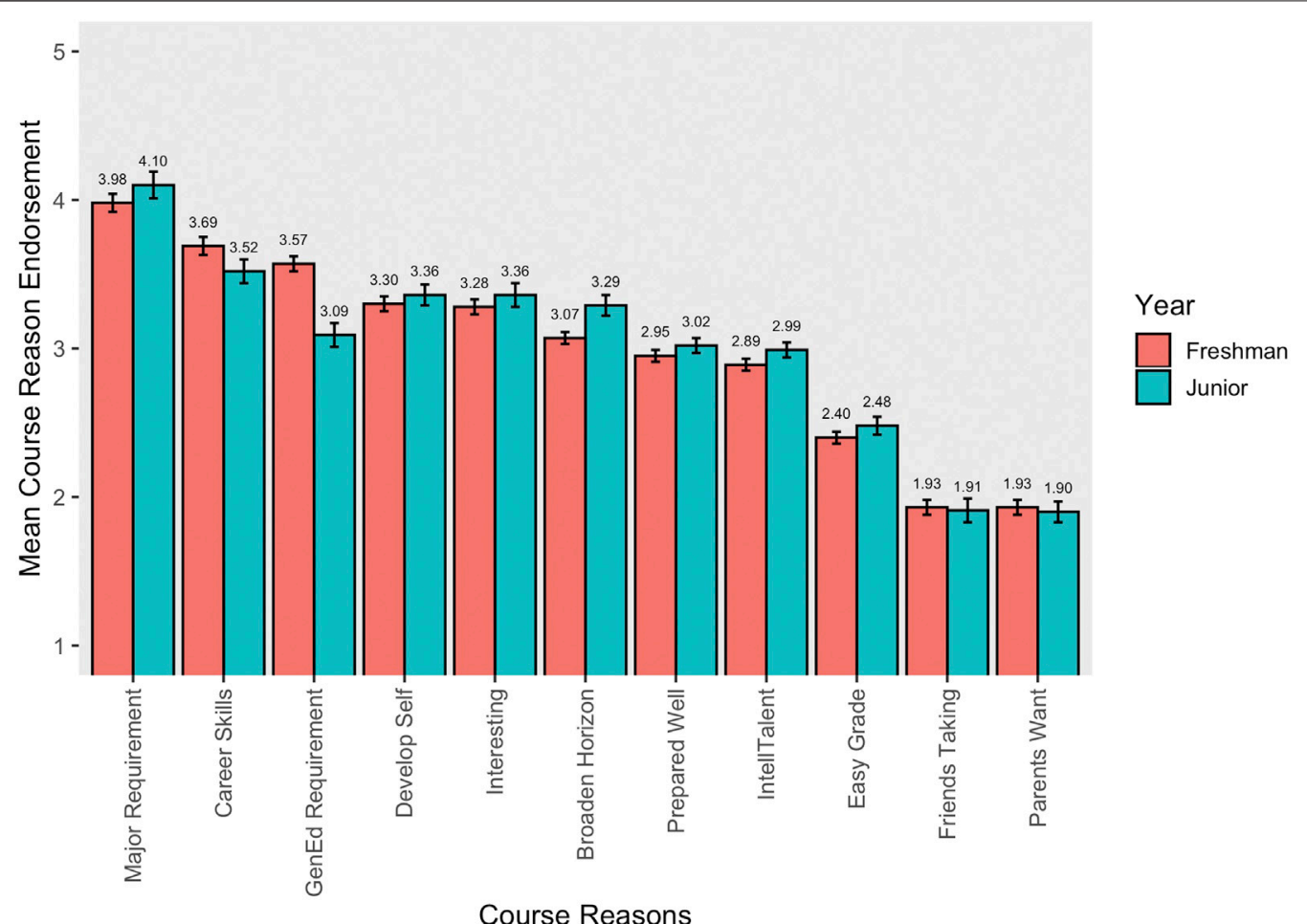

FIGURE 3 | Endorsement of course choice reasons for freshman and junior. Group comparison on endorsement of course choice reasons for freshman (left) and junior (right). Mean and standard errors are presented; 1 = the least important reason choice, 2 = the second and third least important reason choices, 3 = not the least nor most important reason choice, 4 = the second and third most important reason choice, $5=$ the most important reason choice.

\section{Freshman and Junior by Course Reasons}

A repeated measures ANOVA was conducted with course reasons as a within-subject factor and both major and year in school (i.e., freshman vs. junior) as a between-subject factor. We found a statistically significant interaction between course reasons and year, $F(8.240,3,460.862)=4.210, p \leq 0.001, \eta_{p}^{2}=0.010$ (see Figure 3). Pairwise comparisons using Bonferroni correction showed that the mean scores on the rating of course reasons for freshmen were significantly different than juniors for general education requirement (freshman, $3.57 \pm 0.965$; junior, $3.09 \pm$ $0.820 ; p \leq 0.001$ ) and broadening horizons (freshman $3.07 \pm$ 0.709 ; junior, $3.29 \pm 0.809 ; p=0.01$ ). Results did not show a statistically significant interaction between course reasons, major, and year, $F(8.382,3185.249)=1.792, p=0.070, \eta_{p}^{2}=0.005($ see Supplementary Table $\mathbf{S 4}$ for frequencies).

\section{Discipline of Course by Course Reasons}

To examine whether structural settings shape students' course choice, we conducted a repeated measures ANOVA with course reasons as a within-subject factor and discipline of courses clustered into broad categories as a between-subject factor predicting the rating of course reasons. Results showed a statistically significant interaction between course reasons and clustered course discipline on ratings of course reasons, $F(33.848,3528.688)=6.670, p \leq 0.001, \eta_{p}^{2}=0.060($ refer to
Supplementary Table S5 for frequencies). According to pairwise comparisons using Bonferroni correction (see Table 1), students who chose a course in the humanities and arts were less likely to enroll in the course to fulfill their major requirements $(3.43 \pm 0.967)$ than students who chose a course in the social sciences, education, and business $(3.94 \pm 1.127 ; p \leq 0.01)$, biology and health sciences $(4.13 \pm 1.018$; $p \leq 0.001$ ), and physical sciences, computer sciences, and engineering $(4.34 \pm 0.884 ; p \leq 0.001)$. In contrast, students who chose a course in the humanities and arts were more likely to enroll in the course to fulfill their general education requirement $(4.21 \pm 0.907)$ than students who chose a course in the social sciences, education, and business $(3.23 \pm 0.934 ; p \leq 0.01)$, biology and health sciences ( $3.44 \pm 0.858 ; p \leq$ 0.001 ), and physical sciences, computer sciences, and engineering $(3.26 \pm 0.840 ; p \leq 0.001)$. Courses in the humanities and arts were also more likely chosen to develop self $(3.72 \pm 0.844)$ compared to social sciences, education, and business ( $3.25 \pm 0.829 ; p \leq 0.01)$, biology and health sciences (3.21 $\pm 0.684 ; p=0.002)$, and physical sciences, computer sciences, and engineering $(3.24 \pm 0.769 ; p \leq 0.001)$. However, courses in the humanities and arts were less likely chosen to develop career skills $(3.10 \pm 0.900)$ than social sciences, education, and business ( $3.60 \pm 0.916 ; p=0.003)$, biology and health sciences (3.88 $\pm 0.869 ; p \leq 0.001)$, and physical sciences, computer sciences, and engineering ( $3.78 \pm 0.926 ; p \leq 0.001)$. Finally, courses in the social sciences, education, and business were more likely chosen 
TABLE 1 | Endorsement of course choice reasons for course discipline.

\section{$\{X X\}$ is required in your major}

Physical sciences, engineering, and computer science

Social sciences, education and business

Biology and health sciences

Physical sciences, engineering, and computer science

$\{X X\}$ fulfills a general education requirement

Humanities and arts

Humanities and arts

Humanities and arts

Humanities and arts

$\{X X\}$ will be interesting

Social sciences, education, and business

Other

$\{X X\}$ will broaden your horizon

Social sciences, education, and business

Other

$\{X X\}$ will challenge you to develop yourself

Humanities and arts

Humanities and arts

Humanities and arts

$\{X X\}$ will help you develop important skills for the career you want

Social sciences, education and business

Biology and health sciences

Physical sciences, engineering, and computer science

Humanities and arts

Your friend(s) is (are) taking $\{X X\}$

Physical sciences, engineering, and computer science

Physical sciences, engineering, and computer science
Social sciences, education and business

Humanities and arts

Humanities and arts

Humanities and arts

Social sciences, education and business

Biology and health sciences

Physical sciences, engineering, and computer science Other

Physical sciences, engineering, and computer science Physical sciences, engineering, and computer science

Physical sciences, engineering, and computer science Physical sciences, engineering, and computer science

Social sciences, education, and business Biology and health sciences

Physical sciences, engineering, and computer science

Humanities and arts

Humanities and arts

Humanities and arts

Other

Social sciences, education, and business

Biology and health sciences

Significant pairwise comparision using Bonferroni are shown; > refers to which school has the greater mean; 126 courses were in the social sciences, education, and business; 75 courses were in the biology and health sciences; 138 courses were in the physical sciences, engineering, and computer sciences, 70 course were in the humanities and arts; 17 students courses were in other.

for interest $(3.62 \pm 0.726)$ than courses in the physical sciences, computer sciences, and engineering (3.02 $\pm 0.802 ; p \leq 0.001)$.

\section{Other Group Differences by Course Reasons}

Additional group differences by gender of course reasons were identified in Supplementary Analysis (Supplementary Table S6): females rated fulfilling a general requirement and getting a good grade as more important reasons to choose a course than males, and males rated taking a course with friends as more important than females.

\section{DISCUSSION}

First, students rated fulfilling major and general education requirements and acquiring career skills as the most important reasons for taking college courses whether it was expected to be their most difficult or most important course. Apparently, completing major requirements and preparing for future jobs is more salient to students than either interest or self-improvement as rationales for choosing demanding and important courses. Students are responding to both personal and structural reasons in selecting their courses. Given that these two sets of reasons reflect both personal goals and high utility value for achieving one's personal goals with respect to structural requirements, these findings reflect the joint adaptive influence of both agency and structure. Although motivational psychologists might worry that the more extrinsic structural reasons associated with course taking could dampen student engagement, both sociologists and life span developmentalists would see this ordering as reflecting an adaptive level of planned behavior. Consistent with findings grounded in SEVT (Eccles and Wigfield, 2020), these findings suggest that college courses choices are based in the elements of subjective task values rather than success expectations.

In contrast, students regularly rated either more external or more challenge avoidant reasons (e.g., because their parents wanted them to, because their friends were in the course, or because they could get an easy grade) as the least important reasons for taking courses. Furthermore, selecting courses because they felt either well-prepared for them and particularly talented at the subject were rarely picked for either the most or least important reasons.

Further examination of course type by reasons revealed important nuances in endorsement of course choice reasons. Students reported taking a course because they expect it to be interesting and to help them acquire needed career skills more often for their most important course than their most difficult course. Again, these findings suggest that subjective task values of the SEVT framework (i.e., intrinsic and utility value) are particularly important for course choices at university. In 
contrast, they reported fulfilling a college requirement and developing themselves as more important reasons to take their most difficult than their most important course. Thus, to the extent there were differences in the reasons for taking these two types of courses, students focused more on interests, preparation, and career development for the course they expected to be their most important. In contrast, reasons for taking the most difficult course reflect both personal and institutional reasons: to challenge oneself and to fulfill a university general education requirement. Although both of these are quite adaptive reasons to take difficult courses, they likely reflect quite different underlying motivational profiles. One group may be taking the course primarily for extrinsic reasons and may feel unsure of their ability to succeed; the other may be taking the course for intrinsic reasons because they are motivated by challenging themselves to master new material. Motivational theorists argue that the response of these two different types of students to the challenges they might face in such courses will differ (e.g., Eccles and Wigfield, 2020; Ryan and Deci, 2000). We plan to explore such possibilities in future studies.

Results regarding major by reasons also showed significant differences in endorsement of course choice reasons. As one would expect, more students reported fulfilling a major requirement and preparing for a career as reasons to choose a major requirement course than a non-major requirement course. In one way, these findings serve as a validity check on this measure. Similarly, students selected fulfilling a general education requirement and challenging one's self as reasons more often for choosing a non-major requirement course than a major requirement course. Students enrolling in non-major requirement courses enroll in them for either a more extrinsic reason (e.g., general education requirement) or more intrinsic reason $^{3}$ (e.g., challenge to develop yourself). Future studies should investigate which group of students take non-major requirement courses for which reason and whether these students differ in their reactions to experiences in these courses.

Moreover, findings from year in school by reasons for course taking revealed that freshmen chose to enroll in their courses significantly more often for general education requirements than juniors. Whereas juniors chose to enroll in their courses significantly more often for broadening horizons than freshmen. Consistent with our hypothesis, our results suggest that freshmen have more restrictions for their course enrollments than juniors.

Limitations with this study are the large female freshman representation, lack of inclusivity of all the reasons students choose a course, and lack of clarity and nuance in accounts of how participants think about reasons for course choice when answering these surveys questions (e.g., when students choose career skills as the most important reason for course choice, is it because they are interested in helping others or desire money?). Therefore, future studies should aim to recruit a more diverse sample and conduct interviews with current college students about their course choice reasons and thoughts answering the questionnaire.

${ }^{3}$ Intrinsic motivation is defined as motivation based on behaving for one's own sake rather than engaging in an activity for a means to an end and not one's own sake (Ryan and Deci, 2000).

\section{CONCLUSION}

Our results suggest that most college students in this population are taking classes to fulfill job-related college majors. Although this consistent with the current emphasis on college as the pipeline to adult employment, intrinsic motivational theorist would like to see more students taking courses because they want to learn the material for its own sake (Ryan and Deci, 2000). If colleges would like to encourage these course goals to a greater extent, they probably will need to consider ways in which to increase the salience of the intrinsic benefits of taking college courses.

\section{DATA AVAILABILITY STATEMENT}

The raw data supporting the conclusions of this article will be made available by the authors, without undue reservation.

\section{ETHICS STATEMENT}

The studies involving human participants were reviewed and approved by the Institutional Review Board (IRB) at the University of California, Irvine (\#HS: 2018-4646). The patients/participants provided their written informed consent to participate in this study.

\section{AUTHOR CONTRIBUTIONS}

HRL, LVK, and JSE developed the research questions, planned the data analysis, interpreted the results, and drafted the introduction and discussion section. HL drafted the methods, results, and created the Figures. HRL and LVK performed the data analysis. HRL, LVK, JSE, and RA edited and suggested revisions on the final manuscript.

\section{FUNDING}

This research was supported by The Andrew W. Mellon Foundation (1806-05902).

\section{ACKNOWLEDGMENTS}

The authors would like to thank the Next Generation Undergraduate Success Measurement Project team members for help with survey distribution and design.

\section{SUPPLEMENTARY MATERIAL}

The Supplementary Material for this article can be found online at: https://www.frontiersin.org/articles/10.3389/feduc.2021.641254/ full\#supplementary-material. 


\section{REFERENCES}

Archer, M. S. (2014). Structure, agency and the internal conversation. England, United Kingdom: Cambridge University Press, 370.

Chambliss, D. F. (2014). How college works. Cambridge, MA: Harvard University Press, 224.

Dagogo, I. T., Davidowitz, B., and Taylor, D. L. (2019). Third year university students' accounts for choosing chemistry. Afr. J. Res. Math. Sci. Technol. Educ. 23 (2), 135-144. doi:10.1080/18117295.2019.1622208

Deci, E. L., Koestner, R., and Ryan, R. M. (2001). Extrinsic rewards and intrinsic motivation in education: reconsidered once again. Rev. Educ. Res. 71 (1), 1-27. doi:10.3102/00346543071001001

Durik, A. M., Vida, M., and Eccles, J. S. (2006). Task values and ability beliefs as predictors of high school literacy choices: a developmental analysis. J. Educ. Psychol. 98 (2), 382-393. doi:10.1037/0022-0663.98.2.382

Eccles, J. S., Vida, M. N., and Barber, B. (2004). The relation of early adolescents' college plans and both academic ability and task-value beliefs to subsequent college enrollment. J. Early Adolesc. 24 (1), 63-77. doi:10.1177/0272431603260919

Eccles, J. S., and Wigfield, A. (2020). From expectancy-value theory to situated expectancy-value theory: a developmental, social cognitive, and sociocultural perspective on motivation. Contemp. Educ. Psychol. 61, 101859. doi:10.1016/j. cedpsych.2020.101859

Galotti, K. M., and Umscheid, V. A. (2019). Students choosing courses: real-life academic decision making. Am. J. Psychol. 132 (2), 149-159. doi:10.5406/amerjpsyc.132.2.0149

Gottfried, A. E., Marcoulides, G. A., Gottfried, A. W., and Oliver, P. H. (2013). Longitudinal pathways from math intrinsic motivation and achievement to math course accomplishments and educational attainment. J. Res. Educ. Eff. 6 (1), 68-92. doi:10.1080/19345747.2012.698376

Guo, J., Parker, P. D., Marsh, H. W., and Morin, A. J. (2015). Achievement, motivation, and educational choices: a longitudinal study of expectancy and value using a multiplicative perspective. Dev. Psychol. 51 (8), 1163-1176. doi:10.1037/a0039440

IBM Corp. Released (2020). IBM SPSS statistics for macintosh, Version 27.0. Armonk, NY: IBM Corp.

Johnston, J. S., Reardon, R. C., Kramer, G. L., Lenz, J. G., Maduros, A. S., and Sampson, J. P. (1991). The demand side of general education: attending to student attitudes and understandings. J. Gen. Educ. 40, 180-200.

Lauermann, F., Tsai, Y. M., and Eccles, J. S. (2017). Math-related career aspirations and choices within Eccles et al.'s expectancy-value theory of achievementrelated behaviors. Dev. Psychol. 53 (8), 1540-1559. doi:10.1037/dev0000367

Lauermann, F., Chow, A., and Eccles, J. S. (2015). Differential effects of adolescents' expectancy and value beliefs about math and English on math/science-related and human services-related career plans. Int. J. Gend. Sci. Technol. 7 (2), 205-228.
Lent, R. W., Brown, S. D., and Hackett, G. (2002). Social cognitive career theory. Career Choice Dev. 4, 255-311.

Lent, R. W., Lopez, A. M., Jr, Lopez, F. G., and Sheu, H.-B. (2008). Social cognitive career theory and the prediction of interests and choice goals in the computing disciplines. J. Vocat. Behav. 73 (1), 52-62. doi:10.1016/j.jvb.2008.01.002

Meece, J. L., Anderman, E. M., and Anderman, L. H. (2006). Classroom goal structure, student motivation, and academic achievement. Annu. Rev. Psychol. 57, 487-503. doi:10.1146/annurev.psych.56.091103.070258

R Core Team (2018). R: a language and environment for statistical computing. Vienna, Austria: R Foundation for Statistical Computing.

Reese, R. J., and Miller, C. D. (2006). Effects of a university career development course on career decision-making self-efficacy. J. Career Assess. 14 (2), 252-266. doi:10.1177/1069072705274985

Renninger, K. A., and Hidi, S. (2015). The power of interest for motivation and engagement. England, United Kingdom: Routledge, 188.

Ryan, R. M., and Deci, E. L. (2000). Self-determination theory and the facilitation of intrinsic motivation, social development, and well-being. Am. Psychol. 55, 68-78. doi:10.1037/0003-066x.55.1.68

Schunk, D. H., Pintrich, P. R., and Meece, J. (2008). Motivation in education: theory, research, and application. New Jersey, NY: Prentice Hall, 433.

Settersten, R. A., and Gannon, L. (2005). Structure, agency, and the space between: on the challenges and contradictions of a blended view of the life course. Adv. Life Course Res. 10 (05), 35-55. doi:10.1016/s1040-2608(05) 10001-x

von Keyserlingk, L., Becker, M., Jansen, M., and Maaz, K. (2020). Leaving the pondChoosing an ocean: effects of student composition on STEM major choices at university. J. Educ. Psychol. 112 (4), 751-764. doi:10.1037/edu0000378

von Mizener, B. H., and Williams, R. L. (2009). The effects of student choices on academic performance. J. Posit. Behav. Interv. 11 (2), 110-128. doi:10.1177/ 1098300708323372

Conflict of Interest: The authors declare that the research was conducted in the absence of any commercial or financial relationships that could be construed as a potential conflict of interest.

Copyright $\odot 2021$ Lee, von Keyserlingk, Arum and Eccles. This is an open-access article distributed under the terms of the Creative Commons Attribution License (CC $B Y)$. The use, distribution or reproduction in other forums is permitted, provided the original author(s) and the copyright owner(s) are credited and that the original publication in this journal is cited, in accordance with accepted academic practice. No use, distribution or reproduction is permitted which does not comply with these terms. 